되기는 어렵고 영구한 syncytium으로 변화대 버린다. 또 Type 2세포의 특성으로는 lipochrome 염색으로 형 광을 발하고 steroid나 그외의 약제에 의해서 surfactant의 성숙이 촉진된다.

이와 관련해서 알아년 사실로서 steroid가 폐세포 에 대혜서 성장초기에는 세포성장을 촉진시키고 성장 후에는 다단 steroid lecithin synthesis를 증가시킬 뿐 이라는 것이다. 그러고 성숙한 쥐에서는 steroid가 Type 2세포의 hyperplasia와 hyppertrophy를 갖어오 는테 이때의 surface activity는 감소된다.

Lipid synthesis

Johnston일파는 폐와 양수 (amniotic flino)속의 PAP ase(phosphatidic acid phosphohydrolase)에 관해서 중요한 업적을 얻없다. PAPase는 phosphatidylcholine synthesis에 있어서 중요역흴을 하고 있는데 이것이 양 수 속에 더 먼저 나타난다. 그러므로 양수의 PAPase 를 촉정해서 태아의 성숙도를 추측할 수가 있다. 그리 고 PAPase의 측정은 비교적 간단하다는 점과 만약 이것이 폐속에만 있는 것이루면 이것이 가래침이나 혈
액속에서 인정될때는 폐실질의 손상을 의미하는 것이긴 므로 임상적 의의가 많다.

Oxygen Toxicity

$\mathrm{O}_{2}$ toxicity가 동물종류에 따라서 다르다는 것은 확실 하나 아직도 toxicity의 criteria와 tolerance 그리고 폐 손상의 morphologic evidence등에 관해서 불확실한 점 이 많다.

Immunology

대쳬로 폐에는 전신적인 조절과 관계없는 자율적이 고 국소적인 것으로서 B cell-meidiated immunity가 있 다는 것은 공인되였다. 그러나 토 국소적이고 자율적 인 것으로 pulmonary $\mathrm{T}$ cell-medated immumity의 존 재에 관해서는 의견이 구구하다. 그리고 alvealor macrophage가 effector cell의 역흴을 하는지 또는 Lymphokines에 대한 이의 반응에 관해서는 좀더 확실한 연구가 필요하다. Daniele의 실험에서는 lung lavage 에 의해서 얻은 lymphocyte를 사용했는데 이것이 시. 험재료로서의 순도와 적합성을 갖이고 있다고 하기는 매우 어렵다.

(초역자 이찬세)

\title{
2. Nutritional regulation of antibacterial resistance
} \section{영양조절에 의한 병원균에 대한 인체 저항력}

\section{(結核菌이 必要로 하는 必須發育因子의 調節에 依한 先天免疫)}

(문헌) Kochan, I. 1975. Nutritional regulation of antibacterial resistance. p. $273-288$. In D.Schlessinger(ed.), Microbiology-1974. Amer. Soc. Microbiol., Washington, D.C.

結核菌에 街한 先天免疫이 있다고 하면 선듯 믿어지지 않을 것이다. 그러나 BCG接種이나 不奬性感染을 통해

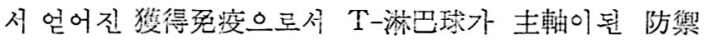

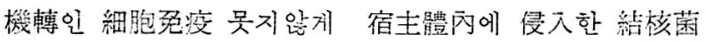

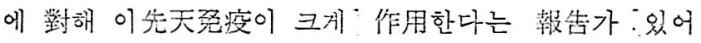
여기에 소개하는 바이다.

어떤 菌이 正常動物體內에 들어와 發育하여 病을 일 으킬려면 宿主의 體液이나 組裁을 energy源으로 또 必 須發育因子토 利用할 수 있어야 한다. 이때까지는 先 天免疫을 어던 營養旒나 必須發育因子를 놓고 宿主와 病原菌사이에서 일어나는 競爭의 結果 菌이 不利하게 되는데서 오는 것으로 보기보다는 어떤 特殊한 抗菌物 質이 存在함으로서 오는 現象으로 보고 그러한 物質을 찾는데 盡力해 왔다. 그러나 菌이 energy源으로서의

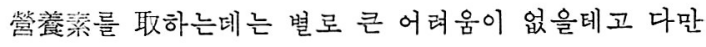
小最의 必須發育因子나 必須金屬ion등은 그들의 量的 調節에 位许 菌의 發有을 抑制할 수 있다.

結核에 있어서도 이러한 現象을 볼 수 있는데 즉 많 은 種類의 哺乳動物의 血清이 結核菌의 必須發有因子 의 하나인 鐵分 $(\mathrm{Fe})$ 의 供級을 制限하여 菌의 發育을 抑制하는 能力이 곧 그 例다. Guinea pig를 除外하 고는 대부분의 哺乳動物血淸이 鐵分含有 transferrin (以下 $\mathrm{Tr}$ 이라 稱함)의 含量이 낮고 그리고 菌이 利

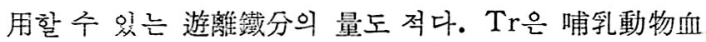
淸內에서 볼 수 있는 蛋白質의 하나로 이는 腸으로부 터 吸收되어 血淸內에 存在하는 鐵分을 붙들어 이를 要 하는 細胞나 組織에 傳達해 주는 役割을 하는데 guinea pig의 血淸은 鐵分含有 $\operatorname{Tr}$ 의 含量도 클 뿐 아니라 遊 離鐵分도 많이 들어 있어서 結核菌에 感受性이 크다. 그런데 鐵分含有 $\operatorname{Tr}$ 이나 遊離鐵分의 含量이 적어서 結 核菌發育抑制力을 가지고 있는 血清에다 鐵分이나 이鐵 分을 chelate하는 菌의 產物인 mycobactin(以下 $\mathrm{M}$ 이라 
稱함) 을 넣어주계 되면 結核菌發育抑制力이 消失되고 만다. $\mathrm{M}$ 은 結核菌의 發育因子가 아니고 血清內에 Tr이 가지고 있는 钱分을 빼앗아다 菌에게 넘겨주는 役割을 하는 物質로서 菌이 鐵分이 缺弱한 生活環境에 처해졌 을 때를 對備해 生痤하는 物質이다. $\mathrm{M}$ 은 또 菌이 食 菌細胞內에 서 ferritin(以下 $\mathrm{F}$ 라 稱함)으로부터 鐵分을 뺏어내는데 큰 役割을 한다. 結核菌은 $\mathrm{F}$ 를 그뎌로 利 用할 수가 없어 이것을 培地에 많이 넣어주어도 菌이 發育하지 못하는데 이 培地에다 $\mathrm{M}$ 을 조금만 넣어주면 發育하는 것으르 보아 위의 견율을 알 수 있다. 絬核菌 의 $\mathrm{M}$ 生産은 培盖基內의 鐵分含量과 聯關이 크서 鐵分

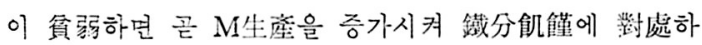
게 된다. 毒力이 弱한 結核菌이나 毒力이 强한 結核菌 이나 生產하는 $\mathrm{M}$ 의뵤은 큰 差異가 없지만 이 物質이 菌 細胞에 結合되어 있는 狀態는 크게 달라서 毒力이强한 菌은 ᄀ 結合이 아주 堅固한테 比해서 毒力이 弱한 菌 은 그렇지 못하다. $\mathrm{M}$ 의 疏水性은 이 物質이 脂肪質 이 豊富하고 毒力이 强한 結核菌과 디 堅固한 結合을 하게 해주는 것으로 본다. 寞로 毒力이 强한 結核菌 인 $\mathrm{H}_{37} \mathrm{R}_{v}$ 가 童力이 弱한 $\mathrm{H}_{37} \mathrm{R}_{a}$ 보다 約 4 倍정도 더 돓은 脂肪質을 含有하고 있다. 즉 菌體와 $\mathrm{M}$ 과의 絬合 狀態는 菌體의 脂肪含量과 관계가 깊고 이는 또 菌의 表力과도 길이 연관되어 있다.

그런데 結榜菌娟와 $\mathrm{M}$ 과의 絬合狀態가 非ion性界面 活性物質에 俰해 크게 影答을 받는다. Tween 80 , Triton WR-1339 및 lecithin과 같은 非ion性界面活 性物質로 惯駿한 結果를 보면 $\mathrm{BCG}$ 나 $\mathrm{H}_{37} \mathrm{R}_{a}$ 는 毒力이 强한 $\mathrm{H}_{37} \mathrm{R}$, 과는 달리 低洪度의 界面活性物質 存在下에 서도 $\mathrm{M}$ 을 잃게된다. 高濃度의 界面活性物質은 현저한 結核菌 發育抑制力을 나타내는테 이는 鐡分이나 $\mathrm{M}$ 을 加䏠주어도 減少되지 않는다. 이러한 界面活性物質의 作用機轉은 이物質이 菌細胞壁에 絬合되어있는 $\mathrm{M}$ 을 消散시키는 作用을 할 뿐만 아니라 鐵分을 붙들고 있 는 $\mathrm{M}$ (M-iron complex)을 菌體가 吸收하는데도 菌細 胞壁의 脂肪과 界面活物性質이 作用하게 되므로서 妨 홈를 하는 것으르 보고있다. 따라서 毒力이 弱한 菌 은 脂肪貿이 壹富하고 最力이 强한 菌보다도 界面活性 物質存在下에서 더 빨리 $\mathrm{M}$ 을 읺어버리기 때문에 이러 한 弱毒菌은 界面活性物質이 많이 들어있는 宿主의 骷 液이나 組徼內에서는 이 物質에 依한 發育抑制에 敏感

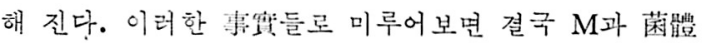
의 結合狀態가 이 菌이 宿主體內에서 生存할 수 있느 냐 없느나하는 점을 決定하게 된다고 본다.

Guinea pig에 BCG를 授種하던가 lipopolysaccharide

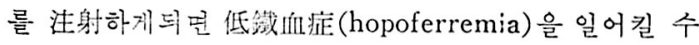

있다. 이는 Tr의 量에는 變化가 오지않고 IfI清內 鐵

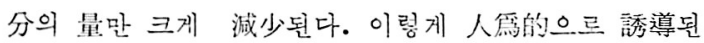
低鐡血症은 곧 結核菌 發有抑制力을 隨件하는데 이러 한 菌發育抑制力의 크기는 血清队鐵分의 量이 얼마나 적으냐에 달려있고 그리고 그것이 얼마나 오래가느 냐 는 低瀻血狀態가 얼마나 持續하느냐에 달려 있는 것이 다. 低鐵血症에 의한 結接菌 發育抑制力은 이것이 自然 的으로 얻어졌건 寊驗的으로 誘導한 것이건 밖에서 鐵 分을 加해주면 그러한 能力이 곧 消失되고만다. 보통 흰쉬나 弱毒菌으로 免疫시킨 흰쥐에 다 結核菌을 感染시 켜놓고 ferric ammonium citrate를 매일 投與하면 두 群다 結核锳病이 보다 쉬이 일어나고 그리고 死亡率도 增加하게된다. 그러나 이러한 鐵分처치가 毒力이 弱한

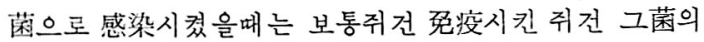
增殖을 촉진시키지 못했다. 이는 試驗管內에서도 界面. 活性物質이 存在하면 毒力이 弱한 菌은 鐵分이나 $\mathrm{M}$ 을 넣어주어도 發育이 증진되지 않는다는 사실을 감안하면 이해된다. 鐵分처치가 $\mathrm{H}_{37} \mathrm{R}_{a}$ 로 免疫시킨 쥐의 結核 菌發育抑制力은 완전히 消失시키지 못했으나 데체로 免疫시킨 動物에 對해 鐵分처치를하면 獲得免疫이 상 당히 減少된다. 先天免疾이나 獲得免疫의 輕減에 있

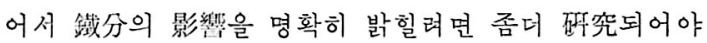
할 것이다. 宿主와 結核菌 사이의 柏互關係에 있어서 宿主의 防䋅力은 $\mathrm{Tr}$ 一鐵分一 $\mathrm{M}$ 의 相互作用에 基礎해서 一次的으로 結核菌의 必須發育要窈인 鐵分의 有用性을 宿主가 얼마나 制呩 할 수 있느냐에 달려 있다고 본다 約 $30 \%$ 의 鐵分舍有 $\mathrm{Tr}$ 을 가지고있는 사람은 結核에 對 해 比較的抵抗力이 있는데 比新서 $85 \%$ 의 鐵分含有 $\mathrm{Tr}$ 을 가지고 있는 guinea pig는 대단히 感受往이 큰 것을 보아서도 先天㤅疫에 있어서 動物種類間에 서 볼 수 있는 差異는 鐵分에 依해 決定되는 差異임을 말해주고 있는 것이다. 結核菌에 對한 쥐의 先天兑疫도 鐵分을 每日注 射함으로서 減少되거나 消失된다. 動物이 內毒紊的作用 을 하는 菌의 構成分에 對해 低鐵血姃으로 反應하는 現 像은 사실상 獲得免疫의 一環이라고 볼 수 있다. 以上 에서 說明한 事實들로 稀少必須營荃紊의 制集에 依한

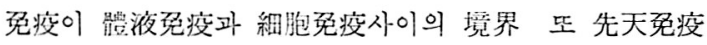
과 獲得免疫사이의 愤界를 잘 연걸시켜준다고 본다. 結核菌과 其他 病原菌卅對䑚 이처럼 營養的冕疫이 存 在한다는 것은 事實이머 이는 稀少成分이나 發育因子의 不有用性에 基礎하고 있다. 이에 關聯된 機轉을 理解. 하게 된면 이로서 새로운 免疫誘導法을 제 공할 수도 있

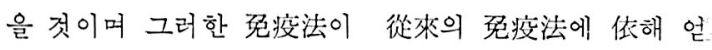
어지는 抵抗力을 능가 할 수 있을런지도 모른다.

(초역자 김상재) 